\title{
Cholesterol Synthesis and Nerve Regeneration
}

\author{
Anne M. Heacock, Paul D. Klinger, Edward B. Seguin, and Bernard W. Agranoff \\ Neuroscience Lab, University of Michigan, Ann Arbor, Michigan, U.S.A.
}

\begin{abstract}
In this report, we examine the requirement of cholesterol biosynthesis and its axonal transport for goldfish optic nerve regeneration. Cholesterol, labeled by intraocular injection of $\left[{ }^{3} \mathrm{H}\right]$ mevalonolactone, exhibited a delayed appearance in the optic tectum. Squalene and other minor components were labeled but not transported. Following optic nerve crush, the amount of labeled cholesterol transport was elevated, while retinal labeling was not altered relative to control fish. A requirement for cholesterol biosynthesis is inferred from the inhibition of neurite outgrowth in retinal explants caused by the cholesterol synthesis inhibitor, 20,25-diazacholesterol. The inhibition of growth could be overcome by addition of mevalonolactone, but not cholesterol, to the medium. Intraperitoneal administration of $200 \mathrm{nmol}$ of diazacholesterol resulted in $92-98 \%$ inhibition of retinal
\end{abstract}

cholesterol synthesis and accumulation of labeled desmosterol and other lipids in fish retina and brain which persisted for 2 weeks. Diazacholesterol-treated fish showed no reduction in the amount of lipid-soluble radioactivity transported following intraocular injection of $\left[{ }^{3} \mathrm{H}\right]$ mevalonolactone, but there were alterations in the chromatographic pattern of the transported labeled lipids. In contrast to its effects on neurite outgrowth in vitro, diazacholesterol did not inhibit optic nerve regeneration in vivo, as measured both by arrival of labeled rapidly transported protein at the tectum and by time required for the return of visual function. Key Words: Diazacholesterol-Axonal transport-Neurite outgrowth-Goldfish retina. Heacock A. M. et al. Cholesterol synthesis and nerve regeneration. J. Neurochem. 42, 987-993 (1984).
During nerve regeneration, the cell body must synthesize and export the components necessary to rebuild the growing axon. The present study focuses on one of these components, cholesterol, a major membrane constituent that is thought to play a role in controlling membrane fluidity. Cholesterol, labeled from radioactive acetate or mevalonate, has been found to be transported rapidly in the chick (Rostas et al., 1979) and rat (Blaker et al., 1980) optic systems, while in the goldfish there is a report of a transient rapid peak of transport, followed by accumulation of radioactivity at a slow rate (Griffith and Larramendi, 1972). Sterol depletion by 25 -hydroxycholesterol treatment has been found to inhibit neurite outgrowth in neuroblastoma (Maltese et al., 1981). In addition, 20,25-diazacholesterol (DAC), which blocks conversion of desmosterol to cholesterol (Thompson et al., 1963), has been reported to inhibit axonal transport of protein in frog sciatic nerve (Longo and Hammerschlag, 1980). In this report, we investigate the various aspects of cholesterol metabolism during regeneration in the goldfish visual system, where in vivo studies of axonal transport and return of visual function, and in vitro studies of retinal explant neurite outgrowth can be carried out. Effects of DAC on nerve regrowth both in vitro and in vivo will be described.

\section{EXPERIMENTAL PROCEDURES}

\section{Materials}

Cholesterol and desmosterol were purchased from Serdary Laboratories. Squalene, mevalonolactone, and fatty acid-free bovine serum albumin were obtained from Sigma Chemical. RS $-\left[5-{ }^{3} \mathrm{H}\right] \mathrm{Mevalonolactone}(10 \mathrm{Ci} /$ mmol), L- $\left[2.3-{ }^{3} \mathrm{H}\right]$ proline $(40 \mathrm{Ci} / \mathrm{mmol})$, and $\mathrm{D}-\left[6-{ }^{3} \mathrm{H}(\mathrm{N})\right]-$ glucosamine hydrochloride $(19 \mathrm{Ci} / \mathrm{mmol})$ were purchased from New England Nuclear. Goldfish (Carassius
Received June 1, 1983; accepted October 6. 1983.

Address correspondence and reprint requests to $B . W$. Agranoff, Neuroscience Lab Building, University of Michigan, 1103 East Huron, Ann Arbor, MI 48109, U.S.A.

The present address of A. M. Heacock is Department of Neu- rology, Albert Einstein College of Medicine, Bronx, New York. U.S.A.

Abbreviations used: DAC. 20.25-Diazacholesterol; MVA. Mevalonic acid; PC. Postcrush. 
auratus), $8-10 \mathrm{~cm}$ in body length, were purchased from Ozark Fisheries, Stoutland, MO.

\section{Methods}

Goldfish optic nerve crush was carried out as previously described (Landreth and Agranoff, 1976). Fish were maintained at $20 \pm 1{ }^{\circ} \mathrm{C}$, unless otherwise stated. Details of the procedure for explant culture of goldfish retina have been described elsewhere (Landreth and Agranoff, 1976; Heacock and Agranoff, 1977). Briefly, retinas were removed from fish 10-15 days following optic nerve crush, cut into $500 \mu \mathrm{m}$ squares with a Mcllwain tissue chopper, then placed onto polylysine-coated $35 \mathrm{~mm}$ tissue culture dishes with supplemented L-15 medium containing $10 \%$ fetal calf serum. The dishes, each containing 16 explants, were then stored in a humidified chamber maintained at $20 \pm 1^{\circ} \mathrm{C}$. For additions to the medium, aliquots of stock solutions of DAC $(0.01 M)$ and/or mevalonolactone $(200 \mathrm{mg} / \mathrm{ml})$ were diluted with complete medium to the desired concentration, then filter-sterilized. The medium was prepared $24 \mathrm{~h}$ prior to use in order to allow time for conversion to mevalonic acid (MVA). The $\mathrm{pH}$ of the medium was then readjusted to $\mathrm{pH} 7.2$ by addition of $\mathrm{NaOH}$. Cholesterol-containing medium was prepared by dilution of a stock solution of cholesterol (10 $\mathrm{mg} / \mathrm{ml}$ in ethanol) with either complete medium or L-15 containing $5 \mathrm{mg} / \mathrm{ml}$ of fatty acid-free bovine serum albumin in place of fetal calf serum. In experiments in which the latter medium was used, explants were grown initially for 2 days in complete medium, in order to allow attachment to the substratum, prior to replacement with albumin-containing medium. The extent of neurite outgrowth (nerve growth index) was estimated as previously described (Landreth and Agranoff, 1979).

For in vivo labeling studies, groups of 6 saline- or DACtreated fish were injected in the right eye with $6-8 \mu \mathrm{Ci}$ [ $\left.{ }^{3} \mathrm{H}\right]$ MVA. After $24 \mathrm{~h}$, the retinas were removed, frozen over dry ice, then stored at $-20^{\circ} \mathrm{C}$ until analysis. The pooled retinas were homogenized in $1.0 \mathrm{ml}$ of ice-cold water, then extracted by addition of $2.0 \mathrm{ml}$ chloroform:methanol (1:1) (Schmitt and Elbein, 1979). The resulting washed lipid extract containing the labeled isoprenoids was analyzed by thin layer chromatography on Brinkmann Silica gel $\mathbf{G}$ plates in hexane:ether:acetic acid (80:20:1) or heptane:toluene $(90: 10)$. The latter solvent was used for separation of squalene and cholesterol ester. Argentation TLC was carried out on plates which had been sprayed with a $40 \%$ aqueous solution of silver nitrate, then activated by heating at $110^{\circ} \mathrm{C}$ for at least $2 \mathrm{~h}$. Following sample application, plates were run in hexane:ether (10:90). Improved separation of cholesterol and desmosterol was obtained by rerunning the plates three more times in the same solvent. The positions of standard cholesterol and desmosterol were detected by charring lanes adjacent to those containing the labeled samples. Distribution of radioactivity was determined by scintillation counting of TLC scrapings or by fluorography of an Enhance (New England Nuclear)-sprayed plate exposed to XRP-5 film at $-70^{\circ} \mathrm{C}$. Prolonged exposures of approximately ten times longer than normal were required to compensate for the quenching effect of the silver nitrate.

For examination of the in vitro effects of DAC on cholesterol synthesis, groups of 6 retinas were incubated at $25^{\circ} \mathrm{C}$ for 4 to $36 \mathrm{~h}$ with $12.5 \mu \mathrm{Ci}$ of $\left[^{3} \mathrm{H}\right] \mathrm{MVA}$ in the medium of Dunlop et al. (1974) or in L-15 medium supplemented with $5 \mathrm{mM}$ glucose, then processed as described above.

For studies of axonal transport of isoprenoids, fish were injected in the right eye with $5 \mu \mathrm{Ci}$ of $\left[{ }^{3} \mathrm{H}\right] \mathrm{MVA}$, and at $12 \mathrm{~h}$ to 48 days later, the right retina and both optic tecta were removed and analyzed for total lipid soluble radioactivity. Since the goldfish visual pathway is crossed, radioactivity in the ipsilateral or right optic tectum serves as a control for systemic labeling, and is subtracted from the value for the contralateral tectum to give the amount of transported radioactivity.

Axonal transport of protein was examined following intraocular injection of $2 \mu \mathrm{Ci}$ of $\left[{ }^{3} \mathrm{H}\right]$ proline, by trichloroacetic acid precipitation of labeled tectal protein as previously described (Elam and Agranoff, 1971). Retinal glycoprotein synthesis was determined similarly following a $90 \mathrm{~min}$ pulse of $\left[{ }^{3} \mathrm{H}\right]$ glucosamine $(10 \mu \mathrm{Ci})$. Protein concentration was determined by the method of Lowry et al. (1951)

Recovery of visual function was measured by shock avoidance responding (Kohsaka et al., 1982). Goldfish were housed individually at $25^{\circ} \mathrm{C}$ throughout the experiment. The left eye was enucleated 7 days prior to crush of the right optic nerve. Fish were given 20 trial sessions in a shuttlebox 4 days and 3 days prior to crush. Each trial consisted of $15 \mathrm{~s}$ of light followed by $20 \mathrm{~s}$ of light plus repetitive shock and then darkness until onset of the next trial. Fish were retested twice weekly. The criterion for recovery of vision was 2 consecutive sessions in which crossing in the light exceeded crossing in the dark by at least 3 responses.

\section{RESULTS}

\section{Axonal transport of cholesterol}

Following intraocular injection of $\left[{ }^{3} \mathrm{H}\right] \mathrm{MVA}$, incorporation into isoprenoids in the retina peaked at $24 \mathrm{~h}$, then subsequently decayed with a $t_{1 / 2}$ of 7 days. At both 1 and 14 days postinjection, $45-49 \%$ of the lipid-soluble radioactivity incorporated into the retina comigrated with cholesterol, while approximately $30 \%$ comigrated with squalene, with the remainder distributed among unidentified compounds. Control and 7 or 14 day postcrush (PC) fish showed the same level of incorporation of $\left[{ }^{3} \mathrm{H}\right] \mathrm{MVA}$ into retinal cholesterol.

The rate of arrival of axonally transported isoprenoids in the tectum of control and 7 day PC fish is shown in Fig. 1. In control fish, no left-right tectum difference was detected until 4 days following precursor injection. In the 7 day $\mathrm{PC}$ fish, no transported radioactivity was detected at the 4 day postinjection interval, since the regenerating nerve does not reach the tectum until 12-14 days PC. Subsequently, the PC fish showed a substantial increase in the amount transported compared with control fish, although the rates of transport were similar in both groups. In a separate experiment (not shown), 14 day PC fish also failed to show rapid transport of cholesterol. Chromatography of 


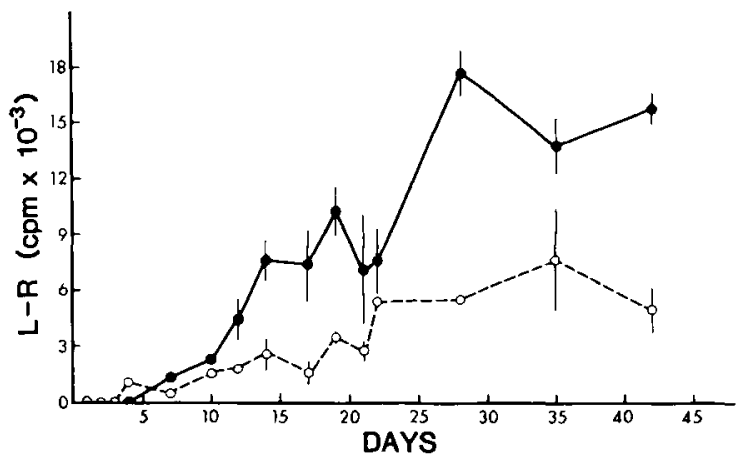

FIG. 1. Rate of axonal transport of cholesterol. Control $(O)$ or 7 day postcrush (-) fish were injected in the right eye with $5 \mu \mathrm{Ci}$ of $\left[{ }^{3} \mathrm{H}\right] \mathrm{MVA}$. At the times indicated, chloroform:methanol-soluble radioactivity in both tecta was determined. Left minus right radioactivity for 2 groups of 3 fish was averaged for each time point [except for the 14 day ( $n$ $=6)$ and 19 day $(n=4)$ time points], each of which gave values for postcrush fish which were statistically different from those of control fish (Student's $t$-test, $p<0.01$ ). Mean $\pm S E M$ radioactivity was $571 \pm 54 \mathrm{cpm}$, in the right tecta of control fish throughout the time course, and was $639 \pm 48$ $\mathrm{cpm}$ in the right tecta of operated fish. The range is indicated by vertical bars.

tectal lipid extracts at 10 days postinjection revealed that all of the transported radioactivity comigrated with cholesterol.

\section{Neurite growth from retinal explants}

Explant cultures of $\mathrm{PC}$ goldfish retina exhibit vigorous neurite outgrowth, and thus offer a convenient preparation in which to investigate the requirement of cholesterol synthesis for neurite extension. DAC $\left(1 \times 10^{-5} M\right)$ was added to the culture medium at the time of explantation, and neurite outgrowth was measured after 5 days in vitro (Table 1). DAC caused a $62-80 \%$ inhibition, which could not be reversed by exogenous cholesterol but was reversed by addition of excess MVA $(1 \mathrm{mg} / \mathrm{ml}$ final concentration). In a separate experiment, a nonsterol metabolite of MVA, dolichol (5 $\mu \mathrm{g} / \mathrm{ml}$ ), was also without effect on the DAC-induced block of outgrowth. Inhibition by DAC and lack of reversibility by cholesterol was demonstrated also in cultures grown in the absence of fetal calf serum (which contains cholesterol). Neurite morphology by phase microscopy was not altered in those explants grown in the presence of $10^{-5} M \mathrm{DAC}$; however, $10^{-4} M$ DAC caused progressive degeneration of pre-existing neurites during the $24 \mathrm{~h}$ after addition to control cultures. This deterioration could be delayed a further $24 \mathrm{~h}$ by the simultaneous presence of $1 \mathrm{mg} / \mathrm{ml}$ MVA.

\section{Effect of DAC on cholesterol synthesis}

Incorporation of $\left[{ }^{3} \mathrm{H}\right] \mathrm{MVA}$ into explant cultures was very low, so incubations of intact retina were then examined to explore further the biochemical mechanism of action of DAC. While significant incorporation into lipid-soluble material (predominantly comigrating with squalene) was obtained, no labeled cholesterol was synthesized under any of the incubation conditions tested. This result was in marked contrast to the efficient incorporation of $\left[{ }^{3} \mathrm{H}\right] \mathrm{MVA}$ into retinal cholesterol in vivo. The in vivo system was, therefore, selected to examine the effect of DAC on cholesterol synthesis in the goldfish visual system.

Intraocular injections of $50 \mathrm{nmol}$ DAC were found to have no effect on total incorporation of [ $\left.{ }^{3} \mathrm{H}\right] \mathrm{MVA}$ into lipid-extractable material in the retina. However, argentation TLC (Fig. 2) revealed a striking inhibition of cholesterol synthesis and the accumulation of radioactivity in desmosterol and other unidentified compounds. Scintillation counting of TLC plate scrapings indicated a 9799\% inhibition of cholesterol labeling at even the lowest dose $(0.2 \mathrm{nmol})$ of DAC tested. Intraperitoneal administration of DAC also resulted in substantial inhibition of retinal cholesterol labeling (Fig. 3), an effect which persisted for up to 14 days following a single injection of DAC. Fish brain cholesterol synthesis was also reduced to $1-3 \%$ of the control values.

\section{Effect of DAC on axonal transport of protein and sterols}

DAC has been reported to inhibit fast axonal transport of protein (Longo and Hammerschlag, 1980). The inhibition of neurite outgrowth seen here might have been the result of such indirect effects of cholesterol synthesis inhibition. The potency of DAC in blocking cholesterol synthesis in vivo per-

TABLE 1. Inhibition of neurite outgrowth by diazacholesterol

\begin{tabular}{|c|c|c|c|c|}
\hline \multirow[b]{2}{*}{ Experiment } & \multicolumn{4}{|c|}{ Nerve growth index } \\
\hline & Control & DAC & $\mathrm{DAC}+$ cholesterol & $\mathrm{DAC}+$ mevalonate \\
\hline 1 & $4.26 \pm 0.80$ & $0.86 \pm 0.14^{a}$ & $0.46 \pm 0.25^{a}$ & \\
\hline 2 & $4.67 \pm 0.16$ & $1.79 \pm 0.29^{a}$ & & $4.77 \pm 0.19$ \\
\hline
\end{tabular}

The nerve growth index of retinal explants was determined after 5 days of culture in control medium or medium containing DAC $\left(I \times 10^{-5} M\right)$, cholesterol $\left(2.6 \times 10^{-5} M\right)$, and/or MVA $\left(6.7 \times 10^{-3} M\right)$. as indicated. All explants were cultured in the presence of $10 \%$ fetal calf serum. Data are expressed as mean \pm SEM for $n=3$ dishes of 16 explants each.

"Statistically different from control at $\mathrm{p}<0.01$. by Duncan"s range test. 


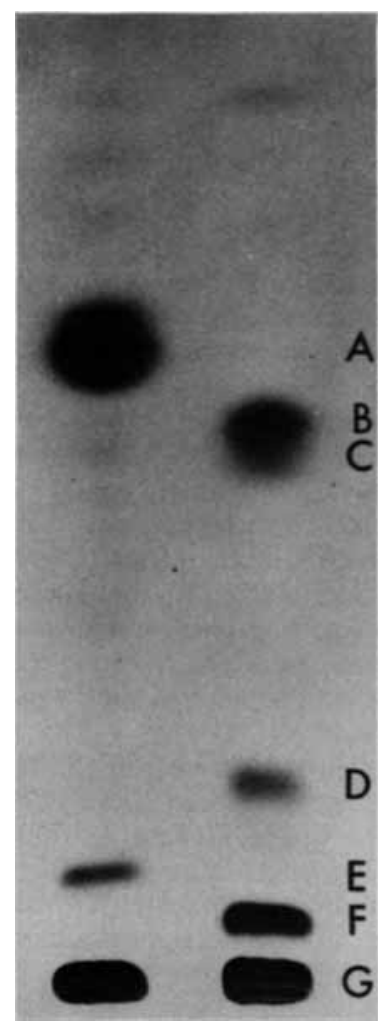

FIG. 2. Fluorography of silver nitrate-thin layer chromatogram of lipid extract from [ $\left.{ }^{3} \mathrm{H}\right] \mathrm{MVA}$-labeled control (left lane) or DAC-treated retina (right lane). The labeled bands $A$ and $B$ comigrate with cholesterol and desmosterol, respectively, while the identity of C, D, E and F are unknown. Radioactivity at the origin (band $G$ ) consists predominantly of squalene.

mitted the examination of this possibility. DACtreated or control fish were injected intraocularly with $\left[{ }^{3} \mathrm{H}\right.$ ]proline, and transport of protein to the tectum was determined at $24 \mathrm{~h}$ or 9 days later (Table 2). No effect of DAC treatment on the amount of labeled transported protein was observed. DAC also did not inhibit detectably protein or glycoprotein synthesis in the retina in experiments in which $\left[{ }^{3} \mathrm{H}\right]$ proline or $\left[{ }^{3} \mathrm{H}\right]$ glucosamine incorporation into trichloroacetic acid-precipitable material in the retina was determined.

While the retinas of DAC-treated fish synthesized very little cholesterol, it was possible that this level of synthesis was sufficient to supply the growing nerve with cholesterol or, alternatively, desmosterol or other sterols might substitute for cholesterol in the membrane of the growing axon. To examine these possibilities, fish ( 20 days $\mathrm{PC}$ ) were administered saline or $200 \mathrm{nmol}$ of DAC intraperitoneally, followed $24 \mathrm{~h}$ later by injection of $12 \mu \mathrm{Ci}$ of $\left[{ }^{3} \mathrm{H}\right] \mathrm{MVA}$. After 10 days, tecta were removed,

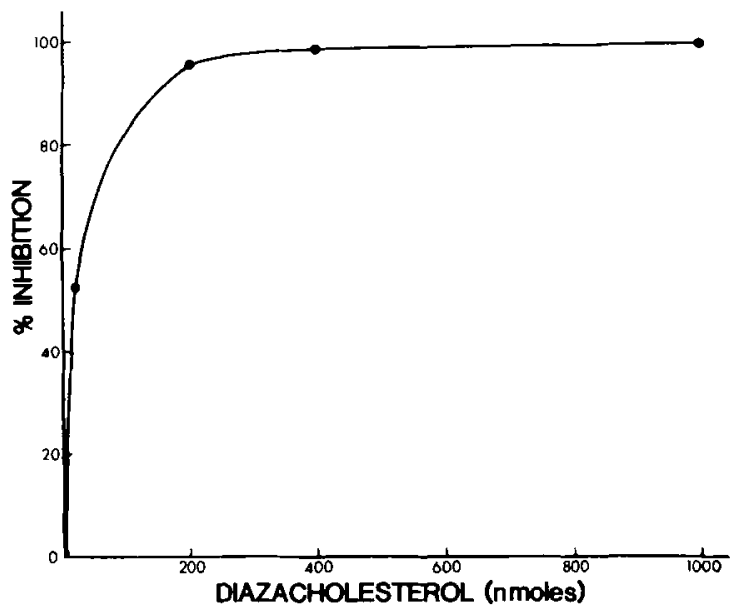

FIG. 3. Inhibition of cholesterol synthesis in vivo by DAC. Groups of 6 fish were injected intraperitoneally with the indicated amount of DAC or with saline. After 6 days, $\left[{ }^{3} \mathrm{H}\right] \mathrm{MVA}$ $(6 \mu \mathrm{Ci})$ was injected in the right eye and $24 \mathrm{~h}$ later, the right retinas from each group were removed and pooled prior to determination of radioactivity in cholesterol, as described in Experimental Procedures. Control fish incorporated $3.68 \times$ $10^{4} \mathrm{cpm} /$ retina into cholesterol.

lipid extracted, and analyzed by argentation TLC. In both saline and DAC-treated fish, $1,800-2,000$ cpm of lipid-soluble radioactivity was transported per tectum. As previously found, in control fish all of the radioactivity comigrated with cholesterol. However, in the DAC-treated fish, there was no labeled cholesterol transported. Most of the radioactivity comigrated with compound $\mathrm{C}$ (as denoted in Fig. 2), which may be similar to a substance reported to accumulate in DAC-treated chick muscle cultures (Rosenblum at al., 1979).

\section{Optic nerve regeneration}

The prolonged action of DAC following intraperitoneal administration made it feasible to determine the effect of DAC on optic nerve regeneration in vivo. In these experiments, two assays were employed: a behavioral test for return of visual function, and measurement of the rapid transport of

TABLE 2. Effect of DAC on axonal transport

\begin{tabular}{lcc}
\hline & $\begin{array}{c}\text { Control } \\
\text { L-R tectal } \\
\text { radioactivity }\end{array}$ & $\begin{array}{c}\text { DAC-treated } \\
\text { (dpm/ } \mu \text { g protein) }\end{array}$ \\
\hline Fast transport & $12.02 \pm 1.56$ & $12.30 \pm 1.44$ \\
Slow transport & $30.77 \pm 3.92$ & $28.78 \pm 2.46$ \\
\hline
\end{tabular}

Fish were injected in the right eye with either $5 \mu$ l of $0.9 \%$ saline or $2 \times 10^{-4} M$ DAC in saline. After $3 \mathrm{~h}$, the same eye was injected with $2 \mu \mathrm{Ci}$ of $\left[{ }^{3} \mathrm{H}\right]$ proline. Twenty-four hours or 9 days later, both optic tecta were removed for determination of axonally transported protein-bound radioactivity. Data are expressed as mean \pm SEM, $n=3$ groups of 4 fish. 
$\left[{ }^{3} \mathrm{H}\right]$ proline-labeled protein from the retina to the tectum. Fish were injected intraperitoneally at the time of optic nerve crush and weekly thereafter with either saline or $200 \mathrm{nmol}$ of DAC. In contrast to the results seen on neurite outgrowth in retinal explants, DAC had no effect on the rate of optic nerve regeneration (Fig. 4).

\section{DISCUSSION}

In a preliminary report, Griffith and Larramendi (1972) described a slow rate of cholesterol transport in the goldfish, preceded by a transient peak of radioactivity in the tectum at $12 \mathrm{~h}$. While we have not been able to confirm the latter observation, the results presented here are consistent with a slow rate of cholesterol transport in the fish. Others, using $\left[{ }^{3} \mathrm{H}\right]$ cholesterol as a tracer, have also observed a slow rate of cholesterol transport in chick optic nerve (Rostas et al., 1979) and chick (McGregor et al., 1973) and mouse (Tang et al., 1974) sciatic nerve, although rapid rates of $\left[{ }^{3} \mathrm{H}\right] \mathrm{MVA}$ or $\left[{ }^{3} \mathrm{H}\right]$ acetate-labeled cholesterol transport have been observed in the rat (Blaker et al., 1980) and chick (Rostas et al., 1979) optic systems. In the goldfish and other species, fast transport of phospholipids has also been reported (Miani, 1963; Currie et al., 1978). While the first appearance of transported phospholipid in the axon is consistent with a rapid rate of transport, there is a slow rate of accumulation in axons and nerve terminals, which is thought to be accounted for by a delayed release of labeled phospholipid from the cell body. A similar delayed release of cholesterol has been described in the rat optic nerve (Blaker et al., 1980). While such a phenomenon could contribute to the observations in the present study, the lack of any indication of rapid transport of labeled cholesterol remains unexplained. It may be that in the fish, rapidly transported cholesterol is incorporated efficiently into the proximal axonal membrane and subsequently slowly diffuses within the membrane to the nerve ending, such that determination of labeled cholesterol in proximal axon segments would be required to detect rapid cholesterol transport. During optic nerve regeneration, the amount of labeled cholesterol transported to the optic tectum was found to increase as much as fourfold, while no increase in incorporation of $\left[{ }^{3} \mathrm{H}\right] \mathrm{MVA}$ into retinal cholesterol was detectable. However, such a response to axotomy of the relatively small population of ganglion cells within the retina cannot be ruled out. An enhanced labeling of transported cholesterol would also result from a decreased turnover of cholesterol in the axonal membrane or from an increased reutilization by tectal cells of cholesterol released from the axon. The enhanced transport of cholesterol
FIG. 4. Effect of DAC on optic nerve regeneration in vivo. A: Arrival of rapidly transported protein in the contralateral optic tectum. Fish were injected intraperitonealiy with $20 \mu$ l of saline (O) or $0.01 \mathrm{MDAC}(\mathrm{O})$ at the time of right optic nerve crush and weekly thereafter. At the indicated times, 3 groups of 3 fish were injected in the right eye with $2 \mu \mathrm{Ci}$ of $\left[{ }^{3} \mathrm{H}\right]$ proline. Protein. bound radioactivity in both tecta was determined $18 \mathrm{~h}$ later. B: Recovery of vision. Groups of 20 fish were injected with saline or 0.01 $M D A C$ as above. Return of visual function was evaluated behaviorally as described in Experimental Procedures.
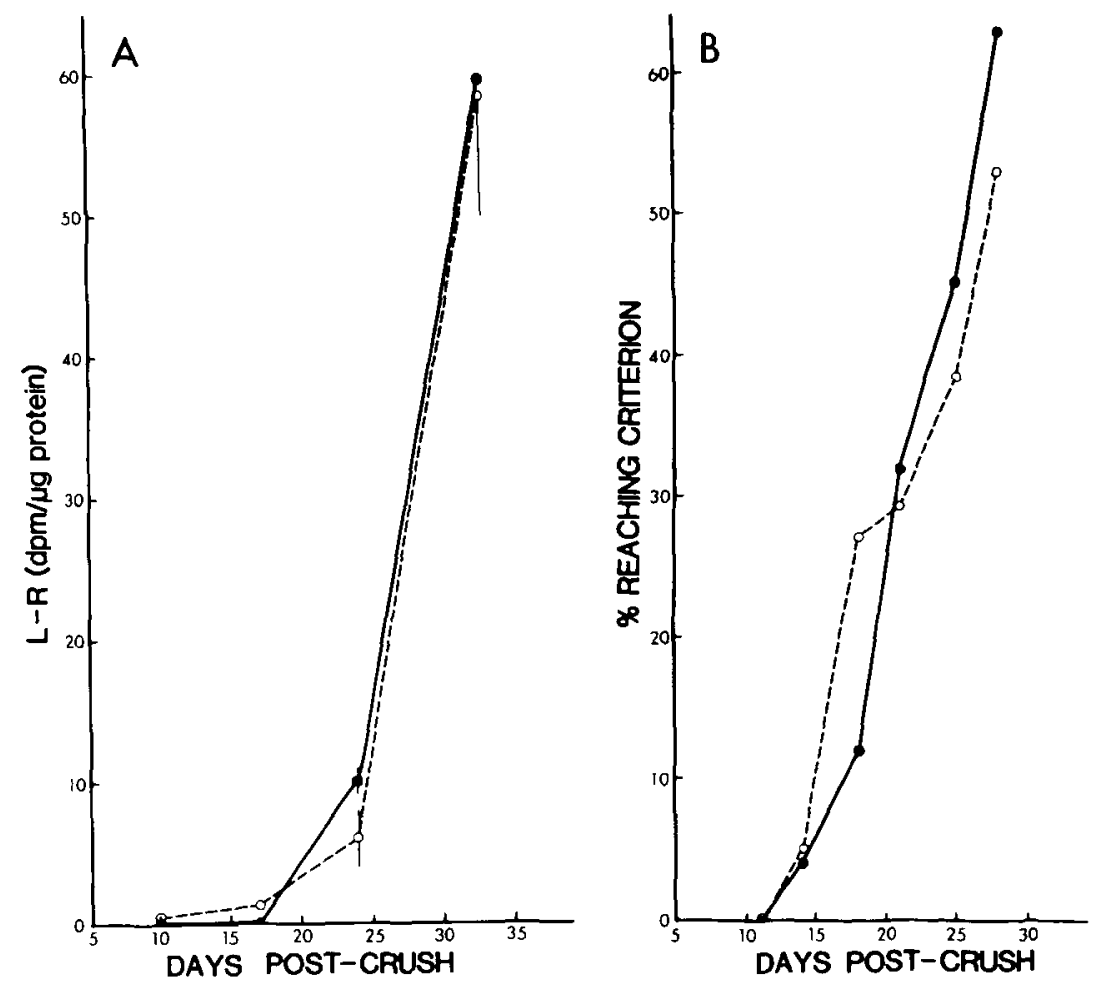
may reflect the requirement of the neuron to elaborate large amounts of new membrane and is in accord with reports of increased transport of phospholipids in regenerating rat sciatic (Dziegielewska et al., 1980; Gould et al., 1982) and rabbit hypoglossal nerves (Alberghina et al., 1982).

Further information on the link between cholesterol synthesis and nerve growth was provided by examination of the effects of DAC, an inhibitor of the $\Delta^{24}$-reductase step in cholesterol synthesis (Thompson et al., 1963) which, when administered to young rats, results in massive accumulation of desmosterol in the brain (Fumagalli et al., 1969; Suzuki et al., 1974; Ramsey, 1977). In the present study, DAC was found to suppress neurite outgrowth from cultured retinal explants, a result in accord with the studies of Maltese and Volpe (1980) and Maltese et al. (1981), who reported neuroblastoma outgrowth inhibition by 25 -hydroxycholesterol, which could be reversed in serum-free cultures by low density lipoprotein (derived from fetal calf serum). This result contrasts with the failure of fetal calf serum to prevent, or exogenous cholesterol to reverse, the inhibition of neurite outgrowth from goldfish retinal explants caused by DAC. It may be that exogenous cholesterol is not taken up by the retinal ganglion cells, or that DAC has effects other than on cholesterol synthesis. The reversal of the growth inhibition by MVA suggests that de novo synthesis of cholesterol is required for neurite outgrowth in these cultures; however, elucidation of the mechanism of this effect is hindered by the known difficulty in demonstrating cholesterol synthesis in vitro (Jones et al., 1971).

The possibility that the effects on nerve growth are due to changes in nonsterol metabolites of MVA deserves consideration, especially in light of recent descriptions of effects of MVA on cell shape or attachment to the culture substratum (Cohen et al., 1982; Schmidt et al., 1982). One of these metabolites, dolichol, was found not to reverse the effects of DAC on neurite outgrowth. In addition, the incorporation of $\left[{ }^{3} \mathrm{H}\right] \mathrm{MVA}$ in vivo into a minor radioactive band comigrating with dolichol was unaffected by DAC. It remains possible that nonsterol metabolites play a role in the effects of MVA on retinal explants.

Although the neurites exhibited no detectable morphological change with $10^{-5} M$ DAC, the involvement of nonspecific membrane effects in the outgrowth inhibition cannot be ruled out. The degeneration of retinal explant neurites caused by $10^{-4} M$ DAC may reflect its reported membrane disrupting effects (Rosenblum et al., 1979).

Another possible mechanism for the neurite outgrowth block is inhibition of axonal transport of protein. In a study by Longo and Hammerschlag (1980), DAC $\left(5 \times 10^{-4} M\right)$ was reported to suppress fast axonal transport in the frog sciatic nerve in vitro. However, in the goldfish visual system, under conditions in which cholesterol synthesis was completely blocked, no effects of DAC on either fast or slow axonal transport were seen. This discrepancy may be due to differences in the concentration of DAC used, since the frog dorsal root ganglion was exposed to concentrations of DAC at least 50 -fold higher than those in the present study. It may be that the inhibition of axonal transport in the frog was due to nonspecific effects of high concentrations of DAC.

Support for the requirement of cholesterol synthesis for nerve growth was sought by examination of the effects of DAC on labeling of cholesterol from $\left.{ }^{3} \mathrm{H}\right] \mathrm{MVA}$ in vivo. DAC proved to be a very potent inhibitor of cholesterol synthesis in vivo, at concentrations similar to those which inhibited neurite outgrowth. As would be predicted from earlier reports, DAC-treated fish accumulated radioactivity in desmosterol, but other unidentified labeled compounds also appeared (Fig. 2). In DAC-treated fish, most of the axonally transported radioactivity was neither in cholesterol nor desmosterol but in an unknown compound. " $C$ ". These results suggest that DAC-inhibition of cholesterol synthesis may not be confined to the $\Delta^{24}$-reductase step.

The profound inhibition of cholesterol synthesis in vivo caused by $\mathrm{DAC}$, taken together with the neurite outgrowth suppression in vitro, suggested that a similar effect on optic nerve regeneration would be seen in vivo. However, neither biochemical nor behavioral measures of regeneration revealed inhibitory effects of DAC. We conclude that either cholesterol is not needed for nerve growth, that other sterols may subsitute for cholesterol in the growing nerve, or that sources of pre-existing cholesterol can compensate for the deficit in newlysynthesized cholesterol. Such sources of cholesterol in the whole animal are not available to the retinal explant in vitro. The tissue culture environment may also place more stringent requirements on the membrane properties of the growing axon, e.g., the need to attach to and grow along a plastic surface. Whatever the reason for the differing outcomes of the in vivo and in vitro experiments, these observations underscore that caution be exercised in generalizing from tissue culture studies to the whole animal.

Acknowledgment: We thank Dr. N. Radin for the gift of diazacholesterol and for helpful discussions and M. R. Lewis for her technical assistance. Supported by NIH Grant NS 13743.

\section{REFERENCES}

Alberghina M., Viola M., and Giuffrida M. A. (1982) Rapid axonal transport of glycerophospholipids in regenerating hypoglossal nerve of the rabbit. J. Neurochem. 40, 25-31. 
Blaker W. D., Toews A. D., and Morell P. (1980) Cholesterol is a component of the rapid phase of axonal transport. $J$. Newrobiol. 11, 243-250.

Cohen D. C., Massoglia S. L., and Gospodarowicz D. (1982) Feedback regulation of 3-hydroxy-3-methylglutaryl Coenzyme A reductase in vascular endothelial cells. J. Biol. Chem. 257, 11106-11112.

Currie J. R., Grafstein B., Whitnall M. H., and Alpert R. (1978) Axonal transport of lipid in goldfish optic axons. Neurochem. Res. 3, 479-492.

Dunlop D. S., Van Elder W., and Lajtha A. (1974) Measurement of rates of protein synthesis in rat brain slices. $J$. Neurochem. 22, 821-830.

Dziegielewska K. M., Evans C. A. N., and Saunders N. R. (1980) Rapid effect of nerve injury upon axonal transport of phospholipids. J. Physiol. 304, 83-98.

Elam J. S. and Agranoff B. W. (1971) Rapid transport of protein in the optic system of the goldfish. $J$. Neurochem. 18, 375387.

Fumagalli R., Smith M. E., Urna G., and Paolelti R. (1969) The effect of hypocholesteremic agents on myelinogenesis. $J$. Neurochem. 16, 1329-1339.

Gould R. M., Spivack W. D., Sinatra R. S., Lindquist T. D., and Ingoglia N. A. (1982) Axonal transport of choline lipids in normal and regenerating rat sciatic nerve. $J$. Neurochem. 39, $1569-1578$

Griffith A and Larramendi L. M. H. (1972) Accumulation of label in goldfish optic nerve and tectum after the intraocular injection of ${ }^{3} \mathrm{H}$-mevalonic acid. Anat. Rec. 173, 320.

Heacock A. M. and Agranoff B. W. (1977) Clockwise growth of neurites from retinal explants. Science 198, 64-66.

Jones J. P., Ramsey R. B., and Nicholas H. J. (1971) Lipid biosynthesis in neuron-enriched and glial-enriched fractions of rat brain: sterol formation. Life Sci. 10, 997-1003.

Kohsaka S., Heacock A. M., Klinger P. D., Porta R., and Agranoff B. W. (1982) Dissociation of enhanced ornithine decarboxylase activity and optic nerve regeneration in goldfish. Dev. Brain Res. 4, 149-156.

Landreth G. E. and Agranoff B. W. (1976) Explant culture of adult goldfish retina: effect of prior optic nerve crush. Brain Res. 118, 299-303.

Landreth G. E. and Agranoff B. W. (1979) Explant culture of adult goldfish retina: a model for the study of CNS regeneration. Brain Res. 161. 39-53.

Longo F. M. and Hammerschlag R. (1980) Relation of somal lipid synthesis to the fast axonal transport of protein and lipid. Brain Res. 193, 471-485.

Lowry O. H., Rosebrough N. J., Farr A. L., and Randall R. J. (1951) Protein determination with the Folin phenol reagent. J. Biol. Chem. 193, 265-275.

Maltese W. A. and Volpe J. J. (1980) Inhibition of de novo sterol synthesis does not affect initiation of neurite outgrowth in neuroblastoma. J. Neurochem. 34, 1522-1526.

Maltese W. A., Reitz B. A.. and Volpe J. J. (1981) Effects of prior sterol depletion on neurite outgrowth in neuroblastoma cells. J. Cell Physiol. 108, 475-482.

McGregor A., Jeffrey P. L., Klingman J. D., and Austin L. (1973) Axoplasmic flow of cholesterol in chicken sciatic nerve. Brain Res. 63, 466-469.

Miani N. (1963) Analysis of the somato-axonal movement of phospholipids in the vagus and hypoglossal nerves. $J$. Neurochem. 10, 859-874.

Ramsey R. R. (1977) Effect of hypocholesterolemic drug treatment on peripheral and central nervous system sterol content of the rat. Lipids 12, 841-846.

Rosenblum E. R., Malloy J. M., McManus I. R., Naworal J. D., and Campbell I. M. (1979) Effect of 20,25-diazacholesterol on viability and steroid synthesis capability of cultured chick embryo pectoral muscle cells. Biochem. Biophys. Res. Commun. 88, 1105-1110.

Rostas J. A. P., Austin L.. and Jeffrey P. L. (1979) Selective labelling of two phases of axonal transport of cholesterol in the chick optic system. J. Neurochem. 32, 1461-1466.

Schmidt R. A., Glomset J. A., Wight T. N., Habenicht A. J. R. and Ross R. (1982) A study of the influence of mevalonic acid and its metabolites on the morphology of Swiss 3T3 cells. J. Cell Biol. 95, 144-153.

Schmitt J. W. and Elbein A. D. (1979) Inhibition of protein synthesis also inhibits synthesis of lipid-linked oligosaccharides. J. Biol. Chem. 254, 12291-12294.

Suzuki K., Zagoren J. C., Chen S. M., and Suzuki. K. (1974) Effects of triparanol and 20.25-diazacholesterol in CNS of rat: morphological and biochemical studies. Acta Neuropathol. (Berl.) 29, 141-156.

Tang B. Y., Komiya Y.. and Austin L. (1974) Axoplasmic flow of phospholipids and cholesterol in the sciatic nerve of normal and dystrophic mice. Exp. Neurol. 43, 13-20.

Thompson M. J., Dupont J., and Robbins W. E. (1963) The sterols of liver and carcass of 20.25-diazacholesterol-fed rats. Steroids 2, 99-104. 